\title{
Sex at Birth
}

National Cancer Institute

\section{Source}

National Cancer Institute. Sex at Birth. NCI Thesaurus. Code C124436.

The physical sexual characteristics of the neonate at birth. 